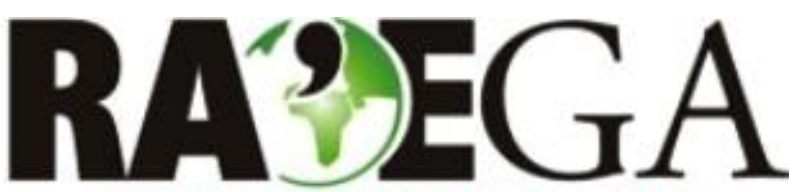

O ESPAÇO GEOGRÁFICO EM ANÁLISE

\title{
CLUSTERIZAÇÃO DE SISTEMAS DE MANEJOS E A CONSTRUÇÃO DE INDICADORES DE SUSTENTABILIDADE UTILIZANDO A METODOLOGIA MESMIS NO TERRITÓRIO PORTAL DA AMAZÔNIA ${ }^{1}$
}

\section{MANAGEMENTS SYSTEMS CLUSTERING AND SUSTAINABILITY INDICATORS OF CONSTRUCTION USING THE METHODOLOGY MESMIS THE TERRITORY AMAZON PORTAL}

\author{
Delmonte Roboredo², Sonia Maria Pessoa Pereira Bergamasco ${ }^{3}$, Anderson Ara ${ }^{4}$, Wagner \\ Gervázio $^{5}$, Thiago Rossi Domingues ${ }^{6}$
}

\section{RESUMO}

O governo brasileiro apoiou irrestritamente a ocupação da Amazônia Legal com créditos altamente subsidiados para substituir a floresta por atividades agropastoris com a justificativa de que precisava ocupar aquela região para soberania nacional. Deste modo, o governo federal investiu fortemente na região, sem nenhuma preocupação ambiental. $O$ objetivo deste trabalho foi identificar agrupamentos familiares homogêneos e o nível de degradação socioambiental desses clusters na Microbacia Hidrográfica Mariana (MBM) localizada no município de Alta Floresta/MT, situada no Território Portal da Amazônia. Para tanto foram estudados os atributos físicos e químicos dos solos, análise das águas superficiais, realização de entrevistas e aplicação da metodologia MESMIS (Marco para la Evaluación de Sistemas de Manejo de Recursos Naturales) para construção de indicadores de sustentabilidade socioambiental. Na clusterização empregou-se quatro técnicas de Estatística Multivariada, as quais indicaram dois sistemas de manejos na microbacia. O marco MESMIS identificou que aquele espaço rural encontra-se muito longe do ideal de sustentabilidade tendo em vista o baixo índice agregado obtido no cluster 1 (35\%) e no cluster 2 $(35,2 \%)$, corroborado pela visão dos atores sociais urbanos que atingiu $40,2 \%$, gerando o índice geral médio de 36,8\%, indicando que a MBM encontra-se na condição "não sustentável ou crítica".

Palavras-chave: Desenvolvimento rural; Agroecossistemas; Agricultura familiar; Análise multivariada.

\section{ABSTRACT}

The Brazilian government unstintingly supported the occupation of the Amazon with highly subsidized credits to replace the forest for agropastoral activities with the justification he needed to occupy the region to national sovereignty. Thus, the federal government has invested heavily in the region, with no environmental concern. The objective of this study was to identify homogeneous family groups and the level of environmental degradation of these clusters in the micro basin Mariana located (MBM) in the municipality of Alta Floresta/MT, located in Macau Amazon Portal. Therefore, we studied the physical and chemical properties of soil, surface water analysis, interviews and application of methodology MESMIS (Marco para la Evaluación Natural Resources Management Systems) to build environmental sustainability indicators. In clustering we used four techniques of multivariate statistics which identified two management systems in the watershed. With the 56 families surveyed indicators were constructed to compare the sustainability between them. The MESMIS March that found that rural areas is far from the ideal of sustainability in view of the low aggregate index obtained in cluster 1 (35\%) and cluster $2(35.2 \%)$, supported by the vision of urban social actors which reached $40.2 \%$, generating the average overall rate of $36.8 \%$, indicating that the MBM is in "not sustainable or critical" condition.

Key-words: Rural development; Agroecosystems; Family farms; Multivariate analysis

\footnotetext{
${ }^{1}$ Trabalho de pesquisa financiado pela Fundação de Amparo à Pesquisa do Estado de São Paulo (FAPESP).

2 Universidade do Estado do Mato Grosso, Cáceres/MT, e-mail: roboredo@gmail.com

3 Universidade Estadual de Campinas, Campinas/SP, e-mail: sonia@feagri.unicamp.br

4 Universidade de São Paulo, São Paulo/SP, e-mail: anderson.ara@icmc.usp.br

${ }^{5}$ Universidade Estadual de Campinas, Campinas/SP, e-mail: wagnergervazioengagro@gmail.com

${ }_{6}^{6}$ Universidade do Estado do Mato Grosso, Cáceres/MT, e-mail: thiagorossimt@gmail.com
} 


\section{CLUSTERIZAÇÃO DE SISTEMAS DE MANEJOS E A CONSTRUÇÃO DE INDICADORES DE SUSTENTABILIDADE UTILIZANDO A METODOLOGIA MESMIS NO TERRITÓRIO PORTAL DA AMAZÔNIA}

\section{INTRODUÇÃO}

O território Portal da Amazônia, constituído por 16 municípios de Mato Grosso que integram a Amazônia Meridional, encontrase com elevada taxa de desflorestamento (ROSA et al., 2013). Nesse espaço há a Microbacia Hidrográfica Mariana formada pelo Rio Taxidermista I, no município de Alta Floresta, cuja paisagem, segundo Bleich e Silva (2013) é constituída por pequenos fragmentos de floresta desconectados da zona ripária. Anteriormente o uso e ocupação dos solos daquele território eram explorados por culturas perenes (café, cacau e guaraná), mas atualmente predomina a bovinocultura de corte e leite (ROBOREDO et al., 2016).

O estudo dessa microbacia é de suma importância por ser a fonte de água que atende as famílias rurais, como também abastece a cidade de Alta Floresta, ecologicamente frágil, e tem importante papel na recarga do Rio Telles Pires e, por sua vez, o Rio Tapajós, responsável pela alimentação do sistema aquífero Alter do Chão (ZOBY e OLIVEIRA, 2005).

O município de Alta Floresta representa uma das frentes de ocupação da Amazônia Meridional por intermédio do projeto de colonização dirigida, realizada pela Colonizadora Indeco S.A. iniciado em 1978 em terras adquiridas do Estado de Mato Grosso (ROSA et al., 2013). Os primeiros produtores começaram a chegar em 1978, em resposta ao forte marketing utilizado pela Colonizadora que era um chamamento extremamente alvissareiro, pois conclamava os colonos do centro-sul do país para a construção de um sonho, o imaginário, o esplendor de um novo dia para aplacar a dor padecida (GUIMARÃES NETO, 2002). Uma nova opção de vida, aonde as famílias poderiam alcançar melhor qualidade de vida, com apoio governamental através de projetos altamente subsidiados obtendo um bom retorno econômico com a exploração das culturas perenes.

No início, os produtores obtiveram bom retorno econômico em virtude do bom preço da produção, assim como as boas condições edafoclimáticas que contribuíram para o alcance de boas produtividades. Entretanto, com o passar dos anos as atividades agrícolas tornaram-se inviáveis economicamente por causa da queda na produtividade gerada pela perda gradual da fertilidade natural do solo, compactação dos solos, baixo preço pago aos produtos agrícolas e a concorrência com o garimpo de ouro.

O espaço rural constitui um ambiente complexo, heterogêneo sob todos os aspectos, devido as particularidades de cada unidade produtiva conduzida por uma família que gestiona os recursos naturais e os bens de produção. Deste modo, identificar os sistemas de manejo, ou a tipologia das unidades produtivas que apresentem características semelhantes, em grupos homogêneos, é importante na busca de entender a diferenciação entre os agricultores. Segundo Gastal et al. (2002), é necessário estudos que permitam caracterizar a variabilidade das condições de produção, tipos de sistemas de produção, zoneamento agroecológico e itinerários técnicos adotados pelas famílias.

Para tanto, Sepúlveda (2008) e Astier et al. (2008), recomendam a adoção de um índice que englobe a multidimensionalidade do espaço pesquisado, envolvendo variáveis quantitativas e/ou qualitativas. Esse índice é constituído por indicadores de sustentabilidade que constituem ferramentas imprescindíveis na identificação de problemas e busca da solução dos mesmos, através da participação e percepção das pessoas que vivem no local da pesquisa (GUIMARÃES e FEICHAS, 2009) e também por intermédio de indicadores analisados em laboratórios (KARLEN e STOTT 1994; IORI et al. 2012). Deve-se ter em mente que um índice dificilmente conseguirá avaliar integralmente a qualidade do ambiente estudado, haja vista a complexidade que envolve o espaço rural.

Os indicadores constituem o termômetro que indica o estado de saúde do sistema, ou seja, reflete o status quo da (in) sustentabilidade das unidades produtivas. De acordo com Doran e Parkin (1994), os indicadores 


\section{CLUSTERIZAÇÃO DE SISTEMAS DE MANEJOS E A CONSTRUÇÃO DE INDICADORES DE SUSTENTABILIDADE UTILIZANDO A METODOLOGIA MESMIS NO TERRITÓRIO PORTAL DA AMAZÔNIA}

utilizados para o monitoramento das unidades produtivas devem ser sensíveis ao manejo, numa escala de tempo que permita sua verificação. Nesta ótica, no tocante aos indicadores físicos do solo, utiliza-se preferencialmente, a densidade, macroporosidade e porosidade para avaliação das condições físicas dos solos, assim como a resistência mecânica do solo a penetração (RMSP) (STOLF, 1991; IORI et al., 2012).

O emprego de indicadores para avaliar a sustentabilidade envolvendo as dimensões técnica, social, econômica e ambiental dos agroecossistemas vem sendo utilizado em diversos estudos de casos em diferentes regiões do mundo, conforme estudos feitos por alguns autores (SPEELMAN et al., 2007; ASTIER et al., 2008; HUMBERTO et al., 2012; YAO et al., 2013).

Autores como Esquivel e Granados (2006), Speelman et al. (2007), Astier et al. (2008) e Ferreira et al. (2011) utilizam a metodologia MESMIS (Marco para la Evaluación de Sistemas de Manejo de Recursos Naturales) para avaliar a sustentabilidade das multidimensões que compõe os agroecossistemas de um território, uma vez que uma de suas prerrogativas é a participação ativa dos atores sociais, sobretudo das famílias rurais na busca da identificação dos problemas e dos caminhos para resolvê-los.

Todavia, o estudo e o entendimento das multidimensões do espaço rural requerem o uso da estatística multivariada para a construção de uma ferramenta apropriada para analisar conjuntamente as variáveis observáveis nas unidades produtivas, sendo estas quantitativas e qualitativas.

Segundo Mingoti (2005), a estatística multivariada consiste em um conjunto de métodos estatísticos aplicados em situações onde inúmeras variáveis são medidas concomitantemente, em cada elemento da amostra. Neste sentido, para a identificação dos sistemas de manejo pode-se utilizar a Análise de Agrupamentos, também conhecida como "Análise de Cluster", que consiste em identificar padrões entre os agricultores, bem como permite classificá-los em subgrupos homogêneos. Um subgrupo é chamado de homogêneo quando seus membros estejam relativamente "próximos", ou seja, os agricultores apresentam perfis semelhantes (HAIR et al., 2005; FASIABEN et al., 2010). Os métodos de Análise de Agrupamentos, ao contrário de outros procedimentos estatísticos, são utilizados na fase exploratória dos dados (HAIR et al., 2005).

O objetivo da pesquisa foi realizar a clusterização dos sistemas de manejos dos adotados nas unidades produtivas, bem como identificar o nível de degradação socioambiental da Microbacia Hidrográfica Mariana no município de Alta Floresta, Mato Grosso, empregando a análise multivariada. Este trabalho defende a hipótese de que aquele território encontra-se degradado social e ambientalmente.

\section{MATERIAL E MÉTODOS}

O estudo foi realizado na Microbacia Hidrográfica Mariana (MBM), localizada no Território Portal da Amazônia, na área periurbana do município de Alta Floresta (latitude 0952'00" e $10^{\circ} 00^{\prime} 00^{\prime \prime} \mathrm{S}$ e longitude $56^{\circ} 09^{\prime} 00^{\prime \prime}$ e $56^{\circ} 06^{\prime} 00^{\prime \prime}$ W). O município é formado por uma área de 8.976 km2 e população de 49.164 habitantes, sendo que $86,9 \%$ residem na zona urbana e $13,1 \%$ na área rural (IBGE, 2010).

O clima do município, segundo a classificação de Köppen, é do tipo Am, com temperatura média anual em torno de $26 \circ \mathrm{C}$ e precipitação média anual em torno de $2800 \mathrm{~mm}$ (ALVARES et al., 2014). A vegetação predominante é a floresta ombrófila aberta (IBGE, 2012).

A definição do número de agricultores pesquisados partiu do universo populacional de 123 unidades produtivas da MBM que foram estratificadas de fração ótima para assegurar representatividade das diversas unidades produtivas (RICHARDSON et al., 2012). Dessa população foram sorteadas 56 unidades produtivas (Figura 1), respaldada na recomendação de Tompkin (1967, p.55) que defende que “... quando somente o número de itens na população é importante, a variância não 


\section{CLUSTERIZAÇÃO DE SISTEMAS DE MANEJOS E A CONSTRUÇÃO DE INDICADORES DE SUSTENTABILIDADE UTILIZANDO A METODOLOGIA MESMIS NO TERRITÓRIO PORTAL DA AMAZÔNIA}

é necessária". Assim, continua o autor, quando o universo amostral for menor do que 5.000 indivíduos, recomenda-se amostragem com 50 indivíduos acrescida de mais $2 \%$ do total da população.

Em cada unidade de produção coletouse amostras de solo e água, assim como foram realizadas entrevistas com os agricultores empregando um questionário contendo questões abertas e fechadas para avaliar a percepção dos agricultores sobre o território da MBM conforme orientação de Richardson et al. (2012). Essas atividades ocorreram no período de agosto de 2011 a setembro de 2013.

\subsection{ANÁLISE DOS SOLOS}

Em todas as propriedades coletou-se amostras de solos em duas áreas: área de preservação permanente (APP) compreendendo uma faixa de 50 metros da margem do recurso hídrico e a área de entorno (ENT) referente a 50 metros que margeia a área da APP amostrada.

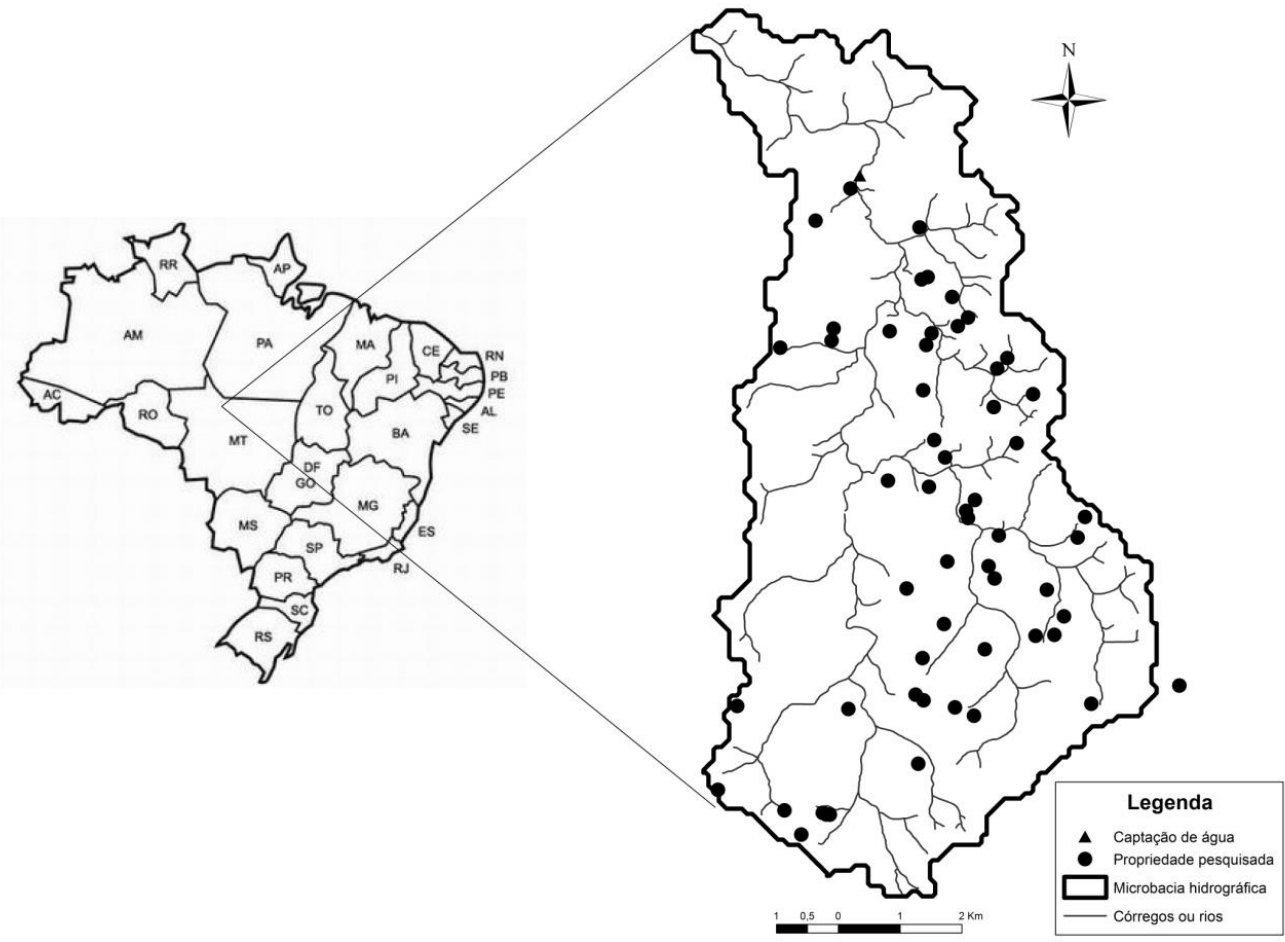

Figura 1 - Espacialização das unidades produtivas pesquisados na MBM. Alta Floresta-MT. Fonte: Os autores (2014).

Nessas áreas amostrou-se os solos nas camadas de 0-0,20 m e 0,20-0,40 m para avaliar a fertilidade $(\mathrm{pH}$, matéria orgânica, potássio, saturação por bases e CTC a pH 7,0) (RONQUIM, 2010) dos solos em 222 amostras compostas para análise química de rotina segundo os critérios da Embrapa (1997). Os dados empregados no presente estudo são produtos da média das duas camadas, exceto a matéria orgânica em virtude do seu decréscimo significativo com a profundidade (CAMARGO et al., 2010). O estudo da qualidade física dos solos foi realizado por meio da densidade, macroporosidade, porosidade total (EMBRAPA, 1997) totalizando 675 amostras indeformadas oriundo de 3 pontos por propriedade, por camada. A resistência mecânica do solo à penetração (RMSP) foi avaliada em três pontos distintos nas duas áreas (APP e ENT), em cada unidade produtiva, até 0,40 $\mathrm{m}$ de profundidade, utilizando um penetrômetro de impacto, com ponteira estreita com área de $1,29 \mathrm{~cm} 2$, seguindo recomendação de Stolf (1991). 


\section{CLUSTERIZAÇÃO DE SISTEMAS DE MANEJOS E A CONSTRUÇÃO DE INDICADORES DE SUSTENTABILIDADE UTILIZANDO A METODOLOGIA MESMIS NO TERRITÓRIO PORTAL DA AMAZÔNIA}

\subsection{AVALIAÇ̃̃o DA QUALIDADE DA ÁGUA}

Avaliou-se a qualidade das águas superficiais por intermédio das seguintes variáveis: oxigênio dissolvido, pH, amônia, fosfato total, biomassa das algas por meio da análise da Clorofila a e percepção dos agricultores quanto a qualidade da água dos rios. $\mathrm{O} \mathrm{pH}$ e a concentração de oxigênio dissolvido na água foram medidos por meio de medidores portáteis. A concentração de amônia (NH3-) e fosfato (PO43-) foi determinada segundo as técnicas descritas em APHA (1998) e a leitura da concentração dos nutrientes foi feita em espectrofotômetro marca Quimis modelo Q798U2M.

A biomassa das algas $(\mu \mathrm{g} / \mathrm{L})$ foi determinada pela extração da "clorofila a" com etanol $90 \%$ aquecido a $780 \mathrm{C}$ e leitura da concentração em espectrofotômetro de acordo com Nush (1980). A variável "clorofila a" é uma das variáveis utilizada na clusterização dos agroecossistemas.

\subsection{TABELA DE CÓDIGOS CONDENSADOS}

O primeiro passo na construção dos indicadores de sustentabilidade socioambiental foi a identificação dos sistemas de manejos da MBM. Para tanto, empregou-se quatro técnicas da estatística multivariada (Análise Fatorial por Correspondências Múltiplas, Análise de Componentes Principais Não Lineares, Análise de Variância Multivariada e Classificação Hierárquica Ascendente) na análise de 89 variáveis (água: 8; solo: 12; socioeconômico-ambiental: 69) e 340 modalidades que compõe a tabela de códigos condensados (TCC). Na análise estatística foi utilizado o ambiente computacional R ( R CORE TEAM, 2015).

Em virtude do grande número (89) de variáveis (indicadores) utilizadas na identificação de grupos homogêneos (cluster) de agroecossistemas pela estatística multivariada será apresentado no Quadro 1 somente as variáveis que apresentaram correlação linear maior do que 0,5 em módulo, bem como aquelas que foram apresentaram significância de $1 \%$ no teste de Kruskal-Wallis na composição dos clusters.

\subsection{ANÁLISE DE AGRUPAMENTOS}

A Análise de Agrupamentos, ou Cluster, consiste em identificar padrões entre os agricultores e permite classificá-los em subgrupos homogêneos. Um subgrupo é chamado de homogêneo caso seus membros estejam relativamente "próximos", ou seja, um grupo homogêneo possui agricultores com perfis semelhantes (HAIR et al., 2005; FASIABEN et al., 2010). A técnica de agrupamento utilizada foi a Classificação Hierárquica Ascendente (CHA).

As medidas de similaridade entre as respostas de cada entrevistado são requeridas e uma medida tradicionalmente utilizada entre variáveis quantitativas é a distância euclidiana definida:

$$
d_{i j}^{2}=\sum_{k=1}^{p}\left(x_{i k}-x_{j k}\right)^{2}
$$

em que $i$ e $j$ são indicadores dos indivíduos em estudo, $p$ o número das variáveis consideradas.

Dentre os critérios de aglomeração em grupos baseados no cálculo das distâncias, adotou-se o método de Ward, uma estratégia de aglomeração baseada na variância geral e na variância entre os agrupamentos (OLIVEIRA, 2000).

\subsection{ANÁLISE FATORIAL DE CORRESPONDÊNCIA MÚLTIPLA}

A análise fatorial de correspondência múltipla (AFCM) consiste de um recurso estatístico multivariado que permite a análise multidimensional de variáveis quantitativas e qualitativas de forma simultânea, operação essa não possibilitada na análise univariada. 0 propósito da AFCM é reduzir a dimensionalidade do sistema, a partir do emprego da métrica de qui-quadrado $\left(\chi^{2}\right)$, identificando grupos com características semelhantes (MINGOTI, 2005). 
ROBOREDO,D. BERGAMASCO, S.M.P.P., ARA,A. GERVÁZIO,W., DOMINGUES,T.R.

\section{CLUSTERIZAÇÃO DE SISTEMAS DE MANEJOS E A CONSTRUÇÃO DE INDICADORES DE SUSTENTABILIDADE UTILIZANDO A METODOLOGIA MESMIS NO TERRITÓRIO PORTAL DA AMAZÔNIA}

Quadro 1 - Variáveis utilizadas na clusterização que apresentaram correlação linear maior do que 0,5 e nível de significantes a $1 \%$.

\begin{tabular}{|c|c|}
\hline Variáveis & Descrição \\
\hline ADUB & Faz ou fez adubação química e/ou orgânica nos últimos três anos \\
\hline CaMg & Somatório dos teores de Cálcio e Magnésio no solo. \\
\hline COMERC & Canal de venda direta para consumidores da produção. \\
\hline CORTE & Exploração da pecuária de corte e qual o destino da produção. \\
\hline CTC & Verifica a CTC a pH 7 dos solos amostrados. \\
\hline EMBALAG & Destino das embalagens de agrotóxicos utilizados na UP. \\
\hline ESCOLAR & Nível de escolaridade do entrevistado. \\
\hline FONTEAG & Captação da água para abastecimento e consumo da família. \\
\hline FOSSA & Estrutura da casa quanto ao depósito de dejetos da família. \\
\hline GALINHA & Criação de galinhas caipiras e qual o destino da produção. \\
\hline INDAGRO & Indústria caseira na UP para beneficiar parte da produção agrícola para melhoria da renda familiar. \\
\hline INDUPEC & $\begin{array}{l}\text { Indústria caseira na propriedade para beneficiar parte da produção pecuária para melhoria da renda } \\
\text { familiar. }\end{array}$ \\
\hline INFPROD & $\begin{array}{l}\text { Somatório de itens de infraestrutura para produção agropecuária: curral, galpão, pocilga, máquinas, } \\
\text { galinheiro, aviário, cerca, etc. }\end{array}$ \\
\hline INTERES & Interesse em revegetar as APP independente da legislação ambiental. \\
\hline LEITE & Exploração da pecuária leiteira e qual o destino da produção. \\
\hline LOGICA & Lógicas adotadas para derrubarem as matas ciliares \\
\hline MATORG & Matéria orgânica do solo. \\
\hline MDO & $\begin{array}{l}\text { Uso da mão de obra do início das atividades na UP até o momento da entrevista (aumentou, } \\
\text { diminuiu ou não houve mudança). }\end{array}$ \\
\hline MDOPERM & $\begin{array}{l}\text { Contrata mão de obra permanente e/ou temporária ou se utiliza somente mão de obra familiar na } \\
\text { UP. }\end{array}$ \\
\hline MICROTRAT & Existência/uso de microtratores na UP com potência inferior a 40 CV. \\
\hline MORADA & Moradia da famílias ocorre na propriedade ou na cidade \\
\hline MUDAM & Mudanças socioeconômicas que ocorreram com a compra da UP \\
\hline PHS & pH em água dos solos. \\
\hline POROTOT & Porosidade total indicador de compactação do solo. \\
\hline POT & Nível de potássio no solo. \\
\hline REDEL & O produtor tem rede de energia elétrica na propriedade. \\
\hline RENDAFUND & Produtor arrenda ou não terras da propriedade para terceiros \\
\hline RENDATRAF & $\begin{array}{l}\text { Origem da principal fonte de renda da familiar se é de atividades agrícolas e não agrícolas, em } \\
\text { outras UP ou em outras localidades. }\end{array}$ \\
\hline TEMPOR & Indica desde quando o produtor é detentor do domínio da UP. \\
\hline TRABFAM & Avalia quantos membros da família moram e trabalham na UP. \\
\hline TRATOR & Emprego de tratores na UP com potência superior a $40 \mathrm{CV}$. \\
\hline UTILIT & $\begin{array}{l}\text { Existência de veículos motorizados usados na propriedade para transporte da produção da unidade } \\
\text { produtiva. }\end{array}$ \\
\hline
\end{tabular}

\subsection{ANÁLISE DE COMPONENTES PRINCIPAIS NÃO-LINEARES}

A análise de componentes principais (ACP) é uma técnica comum para reduzir a dimensionalidade do conjunto de dados, ou seja, projetar as variáveis em um subespaço matemático $R^{m}$ em que $m \ll p m \ll p$, sendo $m m$ a dimensão do novo subespaço e $p$ o número de variáveis consideradas. Porém, a análise de componentes principais não-lineares (ACPNL) possui os mesmos objetivos que $A C P$, porém 


\section{CLUSTERIZAÇÃO DE SISTEMAS DE MANEJOS E A CONSTRUÇÃO DE INDICADORES DE SUSTENTABILIDADE UTILIZANDO A METODOLOGIA MESMIS NO TERRITÓRIO PORTAL DA AMAZÔNIA}

incorpora à essa técnica variáveis nominais e ordinais, e pode encontrar relações não-lineares entre as variáveis

Em suma, a ACPNL encontra as componentes principais através da minimização da seguinte função (FERRARI e MANZI, 2010):

$\sigma^{2}\left(X, q_{1}, \ldots, q_{p}, \beta_{1}, \ldots, \beta_{p}\right)=\frac{1}{p} \sum_{j=1}^{p}\left(X-G_{j} q_{j} \beta_{j}\right)^{\prime}\left(X-G_{j} q_{j} \beta_{j}\right)$

em que $c_{j}$ é um vetor $K_{j}$-dimensional vetor contendo as categorias ordinais da j-ésima variável, $j=1,2, \ldots, p$; $H$ é a matriz contendo as $n$ observações das $p$ variáveis, sendo $H_{j}$ a $j$-ésima coluna, representando a $j$-ésima variável. Sendo $G_{j}$ uma matriz indicadora $n \times K$, tal que $G_{j} c_{j}=$ $h_{j}, \boldsymbol{X}$ uma matriz as $m$-ésimas componentes principais e $\beta_{j}$ um vetor $m$ dimensional com as cargas fatoriais da $j$-ésima variável.

As suposições para minimizar esta função são que $\boldsymbol{X}^{\prime} \boldsymbol{X}=n \mathbf{I}, \boldsymbol{u}^{\prime} \boldsymbol{X}=0$, sendo $\boldsymbol{I}$ a matriz indicadora de ordem $m$ e u um vetor $n$ dimensional, bem como $q_{j} \subset \mathrm{C}$ em que Cé o cone convexo de vetores com elementos não decrescentes.

\subsection{ANÁLISE DE VARIÂNCIA MULTIVARIADA}

A análise de variância multivariada, conhecida como MANOVA (Multivariate Analysis of Variance), é uma extensão da análise de variância clássica (ANOVA), sendo utilizada para um grupo de variáveis dependentes. Ou seja, os testes da ANOVA são realizados para verificar se há diferença estatística de médias entre dois ou mais grupos, enquanto que na MANOVA, têm o objetivo de verificar a semelhança entre os vetores de média de grupos multivariados, explorando simultaneamente as relações entre diversas variáveis independentes e duas ou mais variáveis dependentes (HAIR et al., 2005). Assim, pode-se verificar estatisticamente se um grupo de variáveis possui a mesma média multivariada através da hipótese:

$$
H_{0}:\left(\begin{array}{c}
\mu_{11} \\
\vdots \\
\mu_{p 1}
\end{array}\right)=\left(\begin{array}{c}
\mu_{12} \\
\vdots \\
\mu_{p 2}
\end{array}\right)=\cdots=\left(\begin{array}{c}
\mu_{1 k} \\
\vdots \\
\mu_{p k}
\end{array}\right)
$$

em que $\mu_{i j}$ representa a média da variável $i$, pertencente ao grupo $j$, com $i=1, \ldots, p$ e $j=$ $1,2, \ldots, k$.

Para a realização da análise de agrupamentos este estudo considera o emprego da Análise de Componentes Principais NãoLineares (FERRARI e MANZI, 2010) e do teste de Kruskal-Wallis (SIEGEL e CASTELLAN, 1988) que é um teste estatístico não paramétrico que corresponde a um planejamento completamente aleatorizado quando as suposições clássicas são violadas, exposto a seguir.

\subsection{TESTE DE KRUSKAL-WALLIS}

O teste de Kruskal-Wallis (SIEGEL e CASTELLAN, 1988) é um teste estatístico não paramétrico que corresponde a um planejamento completamente aleatorizado quando a hipótese de normalidade é violada. Os dados consistem de $k$ amostras aleatórias possivelmente dependentes. Denotamos a $i$ ésima amostra de tamanho $n_{i}, i=1,2, \ldots, k$.

As suposições para o teste são: as variáveis aleatórias são mutuamente independentes, contínuas e a escala de medida é pelo menos ordinal.

A estatística $H$ para o teste de KruskalWallis é dada por

$$
H=\frac{\frac{12}{N(N+1)} \sum_{i=1}^{k} n_{i}\left(R_{i}-\frac{N+1}{2}\right)^{2}}{1-\frac{\sum_{i=1}^{g} t_{j}^{3}-t_{j}}{N^{3}-N}}
$$

sendo, $k$ o número de amostras, $k$ o número total de observações, $R_{i}$ a $\mathrm{R}_{\mathrm{i}}$ a soma dos postos para a $i$-ésima amostra, $t_{j}$ o número de 


\section{CLUSTERIZAÇÃO DE SISTEMAS DE MANEJOS E A CONSTRUÇÃO DE INDICADORES DE SUSTENTABILIDADE UTILIZANDO A METODOLOGIA MESMIS NO TERRITÓRIO PORTAL DA AMAZÔNIA}

repetições e $g$ o número de grupos com repetições.

\subsection{MESMIS E A CONSTRUÇÃO DOS INDICADORES DE SUSTENTABILIDADE}

Com base nos dados primários coletados e nas observações de campo registrado no caderno de campo foi sugerido 31 indicadores considerados confiáveis e fáceis de serem obtidos e de suma importância para entender a sustentabilidade do ambiente em estudo. Sarandón (2002, p.405) ressalta a importância do conhecimento dos agroecossistemas quando destaca que “... nuestra correcta elección de los indicadores apropiados depende de la capacidad de comprensión del funcionamiento del sistema."

Todavia como havia vários indicadores técnicos (água e solo) de difícil compreensão e debate, sobretudo para os agricultores, optou-se em trabalhar com 17 indicadores qualitativos, na busca da participação ativa dos atores sociais para que todos pudessem emitir sua percepção qualitativa (Baixa, Média e Alta) sobre os indicadores, conforme preconiza a metodologia MESMIS (ASTIER et al., 2008). Ainda segundo estes autores indicadores qualitativos facilitam a imputação de valores pelos atores sociais, com destaque para os agricultores.

Nesse contexto procurou-se levantar a percepção dos agricultores sobre 17 variáveis (indicadores): 1) fertilidade dos solos; 2) produtividade leiteira; 3) rentabilidade; 4) diversidade agrícola; 5) apoio à comercialização; 6) serviços de ATER (assistência técnica e extensão rural); 7) número de pessoas que moram e exploram as unidades produtivas (UPs); 8) acesso ao crédito rural; 9) participação em associação, cooperativa e sindicato; 10) assoreamento dos rios; 11) recursos próprios (dos agricultores) para recuperar as APPs; 12) dependência de insumos externos; 13) credibilidade dos agentes externos no território da Microbacia Mariana; 14) interesse dos produtores em revegetar as APPs; 15) qualidade da água do rio da propriedade para beber; 16) capacidade suporte das pastagens; e 17) compactação dos solos.

A construção desses indicadores foi realizada em oficinas em duas etapas conforme orientação de Ramos et al. (2013, p.35) que ressalta que oficina se constitui método grupal para "discutir e tratar de problemas e potencialidades, havendo troca de saberes, e experiências vivenciadas, propostas alternativas de soluções inerentes à realidade e devidos encaminhamentos."

A primeira oficina ocorreu no mês de abril/2013 com os atores sociais urbanos que atuavam naquele território, considerados imprescindíveis nesse processo: Secretaria Municipal de Meio Ambiente, Secretaria Municipal de Agricultura, Comissão Executiva do Plano da Lavoura Cacaueira, Empresa Matogrossense de Pesquisa, Assistência Técnica e Extensão Rural, Universidade do Estado de Mato Grosso, Instituto Centro de Vida e Instituto Ouro Verde. Enquanto que a segunda etapa foi realizada em setembro/2013, separadamente, com as famílias dos agricultores integrante de cada cluster para evitar que ficassem constrangidas para se manifestarem devido a presença dos atores urbanos. Nesse processo adotou-se a recomendação de Astier et al. (2008).

\subsubsection{ATRIBUIÇÃO DE PESOS AOS INDICADORES}

Os atores sociais foram separados em grupos por entidades para avaliarem as condições socioeconômicas e ambientais da MBM, como também para atribuírem pesos de 1 (um) a 5 (cinco) (Quadro 2), conforme o grau de importância na ótica de cada um, seguindo o raciocínio de López-Ridaura et al. (2002), Sarandón (2002), Sarandón et al. (2006), e Cerón et al. (2012). Para Sarandón et al. (2006, p.21), “El peso de cada indicador refleja la importancia del mismo en la sustentabilidad". 


\section{CLUSTERIZAÇÃO DE SISTEMAS DE MANEJOS E A CONSTRUÇÃO DE INDICADORES DE SUSTENTABILIDADE UTILIZANDO A METODOLOGIA MESMIS NO TERRITÓRIO PORTAL DA AMAZÔNIA}

Quadro 2 - Peso dos indicadores de sustentabilidade socioambiental.

\begin{tabular}{|c|c|c|c|c|}
\hline \multicolumn{5}{|c|}{ Pesos atribuídos aos indicadores } \\
\hline 1 & 2 & 3 & 4 & 5 \\
\hline Sem importância & Pouca importância & Média importância & Importante & Extrema importância \\
\hline
\end{tabular}

Estes valores nortearam a avaliação da sustentabilidade dos sistemas de manejos comparativamente, sendo que: Baixo (33\%) representa pior condição; Médio (66\%) significa condição intermediária; e Ótimo (100\%), expressa o ideal ou o valor de referência a ser alcançado. Esses índices constituem parâmetros para ter noção da proximidade ou do distanciamento do ambiente pesquisado em relação ao ótimo almejado (GALVÁN-MIYOSHI, 2008).

\subsubsection{PONDERAÇÃO DOS INDICADORES SELECIONADOS PARA AVALIAÇÃO DA MBM}

O primeiro passo consistiu na estandardização - padronização ou normalização - (SEPÚLVEDA, 2008; RAMOS et al., 2010; YAO et al., 2013) dos indicadores na avaliação do ambiente em estudo, procedimento inevitável para indicadores quantitativos e qualitativos posto que normalmente são de diferentes áreas, expressos em diferentes unidades, trazendo-os para uma mesma unidade tornando possível sua integração. Como exemplo, na área ambiental, pode-se ter indicadores que medem assoreamentos ou contaminação dos recursos hídricos por agrotóxicos, ou na área social se mede a acessibilidade ao crédito rural ou a evasão do campo.

Neste trabalho foi adotado o procedimento adotado por Galván-Miyoshi
(2008) e Humberto et al. (2012) para o cálculo do índice ponderado dos indicadores:

- Para casos em que o indicador é considerado como ótimo (100\%) é atribuído a ele a avaliação "alto" (valor de campo). Assim o valor ponderado será igual a: (valor de campo $\mathrm{x}$ 100)/valor ótimo;

- Quando é atribuída ao indicador a avaliação "baixa" (33\%), indica a pior condição na ótica dos atores sociais (idem acima - regra de três direta);

- Todavia se se o ótimo do indicador for baixo (33\%) utiliza-se a regra de três inversa, ou seja, o valor ponderado será igual a: (valor ótimo x 100)/valor de campo. Nessa condição estão incluídos os indicadores: (1) Dependência de insumos externos, (2) Percepção quanto ao assoreamento dos rios e (3) Percepção quanto a compactação dos solos;

- $\quad$ O índice total do sistema será a soma ponderada dividida pela soma dos valores ótimos.

\subsection{3 ÍNDICES AGREGADOS DE SUSTENTABILIDADE SOCIOAMBIENTAL}

Com base no exposto foi elaborado um gradiente contemplando índices de sustentabilidade socioambiental (ISS) em cinco classes (Quadro 3) fundamentado nos trabalhos de Sepúlveda (2008), Ramos et al. (2010) e Cerón et al. (2012).

Quadro 3 - Classes dos índices de sustentabilidade socioambiental.

\begin{tabular}{|c|c|c|c|c|}
\hline \multicolumn{4}{|c|}{ Índices de Sustentabilidade Socioambiental } \\
\hline Insustentável & $\begin{array}{c}\text { Não sustentável ou } \\
\text { Crítico }\end{array}$ & $\begin{array}{c}\text { Moderadamente Sustentável } \\
\text { ou Instável }\end{array}$ & Estável & $\begin{array}{c}\text { Sustentável ou } \\
\text { Ótimo }\end{array}$ \\
\hline ISS $<20$ & $20 \leq$ ISS $<40$ & $40 \leq$ ISS $<60$ & $\begin{array}{c}60 \leq \text { ISS }< \\
80\end{array}$ & $80 \leq$ ISS $\leq 100$ \\
\hline
\end{tabular}




\section{CLUSTERIZAÇÃO DE SISTEMAS DE MANEJOS E A CONSTRUÇÃO DE INDICADORES DE SUSTENTABILIDADE UTILIZANDO A METODOLOGIA MESMIS NO TERRITÓRIO PORTAL DA AMAZÔNIA}

Com os ISS construídos por indicadores e agrupamentos, elaborou-se o gráfico radar para dar maior visibilidade da situação de cada um em relação ao valor ótimo (valor ideal) permitindo, uma noção da proximidade ou distância do ideal a ser alcançado na busca do desenvolvimento sustentável. Esta técnica foi utilizada por LópezRidaura et al. (2002), Esquivel e Granados (2006), Astier et al. (2008), Sepúlveda (2008) e Verona (2010).

\section{RESULTADOS E DISCUSSÕES}

Este trabalho foi realizado em dois momentos distintos. O primeiro na identificação de agrupamentos homogêneos de agricultores (clusters) através das ferramentas da estatística multivariada analisando 89 variáveis (solo, água e socioeconômicos). Enquanto que o segundo momento foi realizado através de oficinas (RAMOS et al., 2013), ocorridas separadamente, para captar a percepção das variáveis qualitativas pelos atores externos (urbanos) e também pelos agricultores dos cluster 1 e cluster 2 .

Para a análise de agrupamentos, considerou-se a análise de componentes principais não-lineares, sumarizando os dados em três componentes. Este número de dimensões foi escolhido por motivos de representação gráfica dos dados e facilidade de interpretação das componentes, uma vez que três dimensões representa o número máximo de dimensões possíveis de serem visualizadas pelo olho humano.

Desta forma, considerou-se três métodos de agrupamentos: utilizando os dados brutos, sem nenhuma transformação no conjunto de dados; padronização, padronizando todas as variáveis no intervalo [0; 1 ; e, por fim, aplicando a análise fatorial de correspondência múltipla (HAIR et al., 2005).

A Tabela 1 exibe os $p$-valores dos testes de hipótese da análise de variância multivariada (MANOVA) para cada uma das abordagens, considerando um número de grupos (K) de 2 a 5 . Assume-se multinormalidade das três componentes principais a $1 \%$ de significância ( $p$ valor $=0.015$ ).

Neste sentido, quanto menor o $\mathrm{p}$-valor (MANOVA) do teste da Tabela 1, maior será o indicativo da diferença estatística entre os agrupamentos (clusters). Uma vez que buscou-se o agrupamento de maior impacto significativo na divisão das componentes, tem-se que a abordagem utilizando os dados brutos e a abordagem utilizando o método de padronização são igualmente eficazes ( $p$-valor $=3.4 \mathrm{E}-19$ ). Ambas sendo mais eficazes que os agrupamentos criados através da AFCM. Desta forma, selecionou-se o método de padronização pela presença de variáveis com muitas categorias. A Figura 2 exibe o dendograma com os dois agrupamentos identificados: Cluster 1 e Cluster 2 compostos, respectivamente, por 45 e 11 unidades produtivas.

Um ponto importante a ser notado é que, através do dendograma, é difícil estabelecer um momento de corte para os grupos. Visualmente o dendrograma seria dividido entre 2 ou 3 grupos, respectivamente para as distâncias euclidianas de 10 e 9. O teste realizado pela MANOVA (Tabela 1), dá fim a esta subjetividade, indicando que a melhor divisão estatística dos dados é realizada considerando 2 grupos $(\mathrm{K}=2)$. 
ROBOREDO,D. BERGAMASCO, S.M.P.P., ARA,A. GERVÁZIO,W., DOMINGUES,T.R.

\section{CLUSTERIZAÇÃO DE SISTEMAS DE MANEJOS E A CONSTRUÇÃO DE INDICADORES DE SUSTENTABILIDADE UTILIZANDO A METODOLOGIA MESMIS NO TERRITÓRIO PORTAL DA AMAZÔNIA}

Tabela 1 - Método de análise de agrupamento utilizado nos sistemas de manejos da MBM. Alta FlorestaMT.

\begin{tabular}{ccc}
\hline Métodos de Agrupamento & $\begin{array}{c}\text { Tamanho dos } \\
\text { Grupos (K) }\end{array}$ & $\begin{array}{c}\text { MANOVA } \\
\text { (p-valores) }\end{array}$ \\
\hline \multirow{3}{*}{ Dados Brutos } & 2 & $3.4 \mathrm{E}-19$ \\
& 3 & $2.0 \mathrm{E}-09$ \\
& 4 & $9.0 \mathrm{E}-07$ \\
Padronização & 5 & $6.6 \mathrm{E}-06$ \\
\hline & 2 & $3.4 \mathrm{E}-19$ \\
& 3 & $3.6 \mathrm{E}-07$ \\
AFCM & 4 & $2.0 \mathrm{E}-04$ \\
& 5 & $2.8 \mathrm{E}-04$ \\
\hline & 2 & $3.3 \mathrm{E}-16$ \\
& 3 & $2.2 \mathrm{E}-09$ \\
& 4 & $5.2 \mathrm{E}-13$ \\
& 5 & $6.1 \mathrm{E}-07$ \\
\hline
\end{tabular}

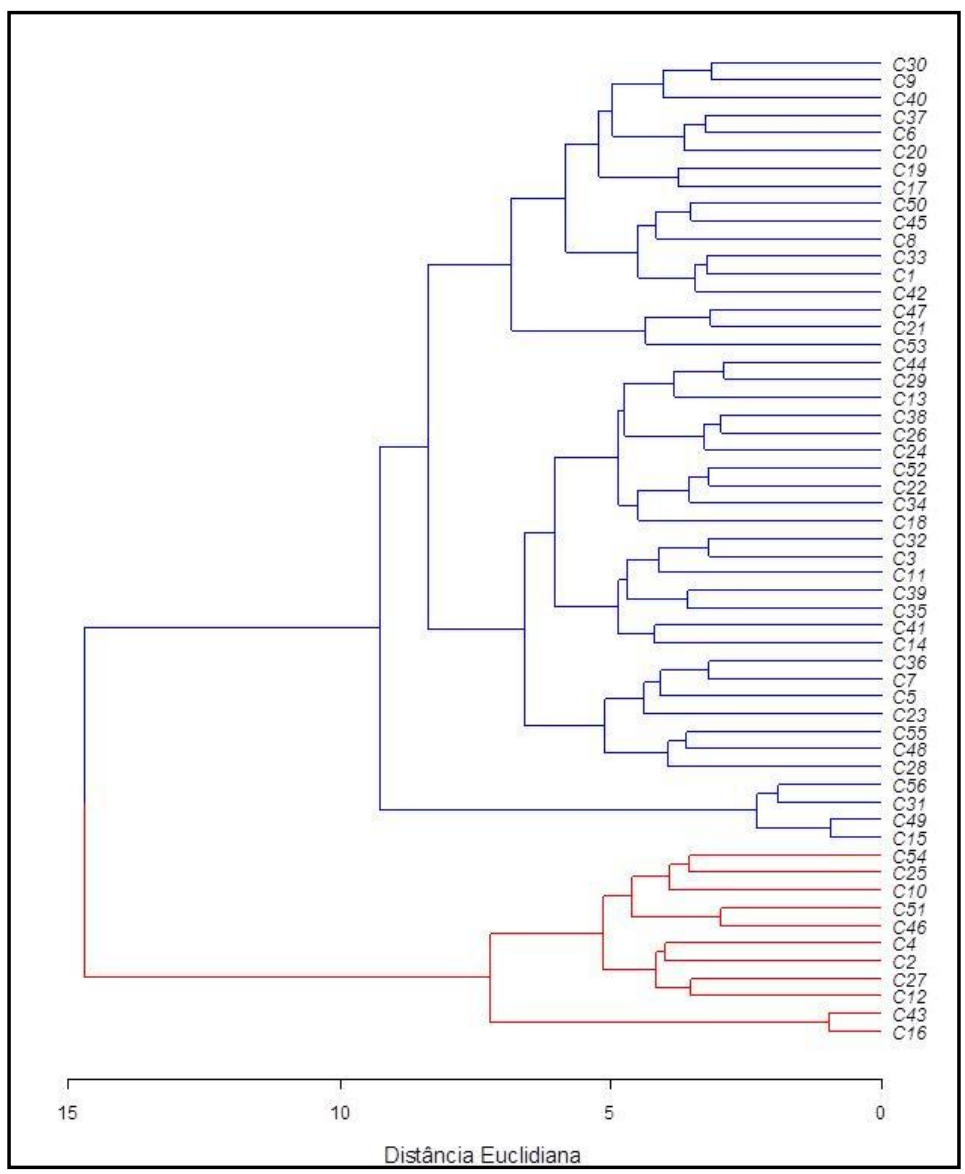

Figura 2 - Dendograma com os dois sistemas de manejos da MBM. Alta Floresta-MT. Fonte: Os autores (2014).

\subsection{INTERPRETAÇÃO DOS GRUPOS}

Para realizar a interpretação dos agrupamentos, a análise de componentes principais não-lineares foi novamente considerada. A correlação linear entre todas as três componentes (PC1, PC2 e PC3) e das 101 variáveis avaliadas estão exibidas na Tabela 2 , apenas as 23 variáveis que tiveram uma 


\section{CLUSTERIZAÇÃO DE SISTEMAS DE MANEJOS E A CONSTRUÇÃO DE INDICADORES DE SUSTENTABILIDADE UTILIZANDO A METODOLOGIA MESMIS NO TERRITÓRIO PORTAL DA AMAZÔNIA}

correlação linear maior de 0,5, em módulo, isto é, maior que 0,5 ou menor que $-0,5$.

Analisando a Tabela 2 nota-se que a variável nível de Potássio na área de APP (POTAPP) aumenta o valor da primeira componente principal, uma vez que outras variáveis diminuem a primeira componente, sendo estas: FONTEAG; FOSSA; REDEL; MICROTRAT; UTILIT; INFPROD; MDOPERM; RENDATRAF; COMERC; INDAGRO; INDUPEC; EMBALAG; MUDAM; INTERES e MORADA.

Desta forma, pode-se interpretar a primeira componente principal (PC1) como um contraste entre a riqueza dos teores de Potássio na área de APP e a riqueza tecnológica dos agricultores (sumarizados pelas variáveis MORADA, FONTEAG, FOSSA, REDEL, MICROTRAT, UTILIT, INFPROD, MDOPERM, RENDATRAF, COMERC, INDAGRO, INDUPEC, EMBALAG, MUDAM, INTERES). Quanto maior esse componente maior será a riqueza nas propriedades químicas na área de APP, especialmente o Potássio. Quanto menor esta componente maior a riqueza tecnológica do agricultor.

A segunda componente principal é aumentada pela variável relativa ao emprego de mão de obra (MDO) e diminuída pelas variáveis relativas ao tempo que o agricultor é detentor do domínio do imóvel rural (TEMPOR) e pela lógica no desmatamento das matas ciliares na abertura das propriedades (LOGICA).

Desta forma, pode-se interpretar a segunda componente (PC2) como um contraste do emprego de mão de obra e a consciência temporal do desmatamento. Quanto maior este componente, maior será o emprego da mão de obra e quanto menor esta componente há mais tempo o agricultor estará localizado na propriedade, bem como possuirá uma lógica mais sustentável para a derrubada das matas ciliares.

A terceira componente (PC3) é aumentada significativamente pelas boas propriedades químicas do solo, tanto na área de APP quanto na área de entorno.

A Tabela 3 exibe as médias de cada componente principal para cada um dos grupos criados pela análise de agrupamento. Através desta, pode-se interpretar como os dois grupos definidos se comportam nas três dimensões construídas pela análise de componentes principais não-lineares. 
ROBOREDO,D. BERGAMASCO, S.M.P.P., ARA,A. GERVÁZIO,W., DOMINGUES,T.R.

\section{CLUSTERIZAÇÃO DE SISTEMAS DE MANEJOS E A CONSTRUÇÃO DE INDICADORES DE SUSTENTABILIDADE UTILIZANDO A METODOLOGIA MESMIS NO TERRITÓRIO PORTAL DA AMAZÔNIA}

Tabela 2 - Correlação linear entre as componentes e variáveis coletadas na MBM. Alta Floresta-MT.

\begin{tabular}{|c|c|c|c|}
\hline Variável & PC1 & PC2 & PC3 \\
\hline POROTOTAPP & 0.024 & 0.012 & 0.595 \\
\hline CTCAPP & 0.401 & 0.221 & 0.515 \\
\hline CTCENT & 0.402 & 0.203 & 0.550 \\
\hline CaMgAPP & 0.400 & 0.132 & 0.561 \\
\hline POTAPP & 0.526 & 0.218 & 0.335 \\
\hline MORADA & -0.764 & 0.017 & -0.083 \\
\hline TEMPOR & -0.099 & -0.692 & 0.336 \\
\hline FONTEAG & -0.601 & 0.164 & 0.118 \\
\hline FOSSA & -0.527 & 0.196 & 0.275 \\
\hline REDEL & -0.606 & 0.132 & 0.153 \\
\hline MDO & -0.006 & 0.520 & -0.384 \\
\hline MICROTRAT & -0.734 & -0.105 & -0.256 \\
\hline UTILIT & -0.541 & 0.262 & 0.121 \\
\hline INFPROD & -0.555 & 0.011 & 0.247 \\
\hline MDOPERM & -0.741 & 0.057 & 0.211 \\
\hline RENDATRAF & -0.652 & 0.016 & 0.155 \\
\hline COMERC & -0.761 & 0.093 & 0.053 \\
\hline INDAGRO & -0.824 & 0.232 & 0.094 \\
\hline INDUPEC & -0.798 & 0.257 & 0.141 \\
\hline EMBALAG & -0.715 & 0.042 & -0.232 \\
\hline LOGICA & -0.013 & -0.551 & -0.019 \\
\hline MUDAM & -0.650 & 0.064 & -0.062 \\
\hline INTERES & -0.515 & 0.119 & 0.184 \\
\hline
\end{tabular}

POROTOTAPP = Porosidade total na APP; CTCAPP =CTC na APP; CTCENT = CTC no entorno; CaMgAPP = Cálcio + Magnésio na APP; POTAPP =potássio na APP. Fonte: Os autores (2014).

Tabela 3 - Correlação linear entre as componentes e variáveis coletadas na MBM. Alta Floresta-MT.

\begin{tabular}{l|c|c|c|c}
\hline \multirow{2}{*}{ Agrupamentos } & Unidades & \multicolumn{3}{|l}{ Médias $\times 100$ para cada Componente Principal } \\
\cline { 3 - 5 } & Produtivas & PC1 & PC2 & PC3 \\
\hline Cluster 1 & 45 & -0.598 & 0.099 & -0.023 \\
Cluster 2 & 11 & 2.446 & -0.406 & 0.093 \\
\end{tabular}

Fonte: Os autores (2014).

Através das Tabelas 1 e 2, pode-se interpretar os resultados baseando-se no comportamento das médias de cada uma das três componentes, ou seja, a cada média exibida na Tabela 3 será dada uma interpretação baseada no relacionamento das componentes e das variáveis. Pelos resultados obtidos os clusters identificados apresentam seguintes características:

Cluster (1): Agrupamento formado por agricultores que utilizam melhor os recursos tecnológicos se comparado ao grupo 2, alto 


\section{CLUSTERIZAÇÃO DE SISTEMAS DE MANEJOS E A CONSTRUÇÃO DE INDICADORES DE SUSTENTABILIDADE UTILIZANDO A METODOLOGIA MESMIS NO TERRITÓRIO PORTAL DA AMAZÔNIA}

emprego da mão de obra e com razoáveis propriedades químicas de solo na área de entorno e de APP. Sendo este o perfil mais frequente dos agricultores analisados $(n=45$, cerca de $80 \%$ da amostra);

Cluster 2: Agrupamento formado por agricultores com baixa riqueza tecnológica, que estão há mais tempo na propriedade e adquiram lógica mais sustentável para a derrubada das matas ciliares. Tendo um elevado valor das propriedades químicas tanto na área de entorno quanto na área de APP. Sendo este o perfil menos frequente dos agricultores analisados ( $n=11$, cerca de $20 \%$ da amostra).
A Figura 3 exibe o comportamento dos agricultores para os dois grupos, considerando as três dimensões criadas pela análise de componentes principais não-lineares. Enquanto que a Figura 4 indica os agricultores que, dentro dos grupos, mais se distanciam dos demais, em seus respectivos agrupamentos.

\subsection{VARIÁVEIS SIGNIFICATIVAS NA CLUSTERIZAÇÃO}

A Tabela 4 exibe os $p$-valores do teste de Kruskal-Wallis, que indicam as variáveis mais significativas na composição dos dois clusters de agricultores, considerando uma significância de $1 \%$.

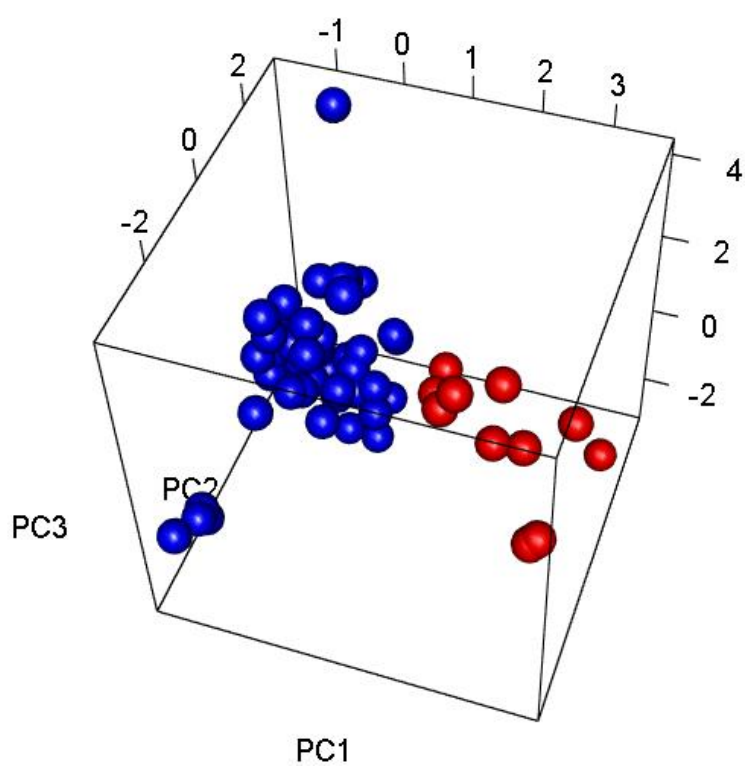

Figura 3 - Visualização dos agricultores nas três componentes principais, categorizados por agrupamento. Alta Floresta-MT. Fonte: Os autores (2013).

Desta forma, verifica-se que as variáveis maliADOPERM; RENDATRAF; COMERC; INDAGRO; INDUPEC; significativas ( $p$-valor <0,001), dentre as expostas rEABALAG; MUDAM e REDEL.

Tabela 4, são: MORADA; MICROTRAT; TRATOR; UTILIT; 


\section{CLUSTERIZAÇÃO DE SISTEMAS DE MANEJOS E A CONSTRUÇÃO DE INDICADORES DE SUSTENTABILIDADE UTILIZANDO A METODOLOGIA MESMIS NO TERRITÓRIO PORTAL DA AMAZÔNIA}

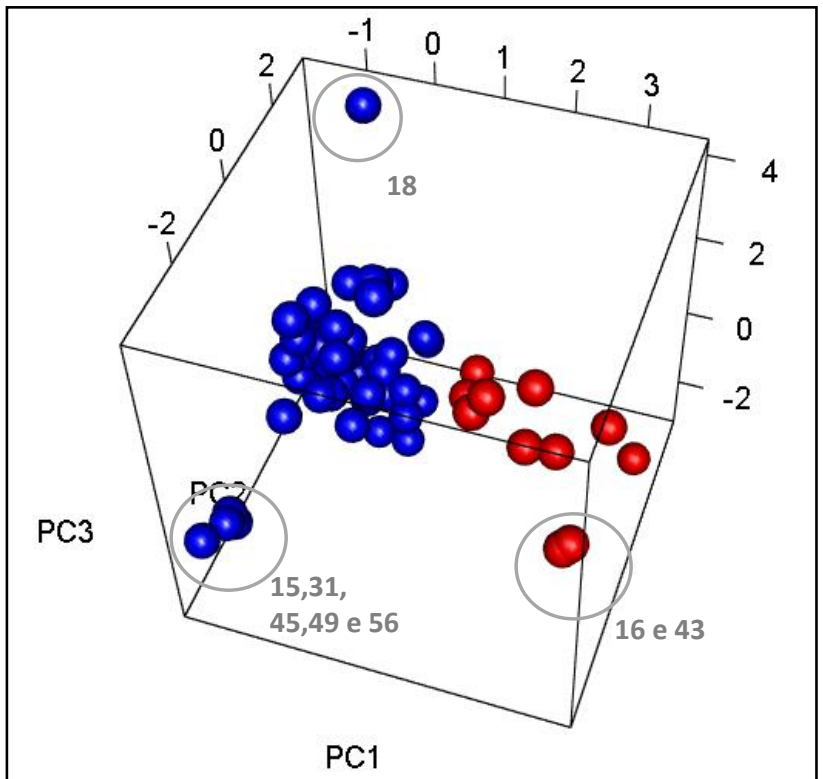

Figura 4 - Visualização dos agricultores mais distantes em cada um dos grupos. Alta Floresta-MT. Fonte: Os autores (2013).

Tabela 4 - Teste Kruskal-Wallis para o impacto das variáveis na composição dos grupos da MBM. Alta FlorestaMT.

\begin{tabular}{l|c|l|c}
\hline \multicolumn{1}{c|}{ Variáveis } & p-valor & \multicolumn{1}{c}{ Variáveis } & p-valor \\
\hline MORADA & $<0.001$ & GALINHA & 0.001 \\
MICROTRAT & $<0.001$ & RENDAFUND & 0.001 \\
TRATOR & $<0.001$ & POTENT & 0.001 \\
UTILIT & $<0.001$ & POTAPP & 0.002 \\
MDOPERM & $<0.001$ & MATORGENT & 0.002 \\
RENDATRAF & $<0.001$ & CaMgAPP & 0.004 \\
COMERC & $<0.001$ & INTERES & 0.004 \\
INDAGRO & $<0.001$ & ADUB & 0.006 \\
INDUPEC & $<0.001$ & pHSENT & 0.006 \\
EMBALAG & $<0.001$ & FONTEAG & 0.007 \\
MUDAM & $<0.001$ & LEITE & 0.007 \\
REDEL & $<0.001$ & FOSSA & 0.007 \\
TRABFAM & 0.001 & CORTE & 0.009 \\
ESCOLAR & 0.001 & &
\end{tabular}

POTENT = potássio no entorno; POTAPP =potássio na APP; MATORGENT = matéria orgânica no entorno; CaMgAPP = Cálcio + Magnésio na APP; $p H S E N T$ = pH do solo no entorno. Fonte: Os autores (2014).

Desta forma, estes resultados indicam a confirmação estatística da diferença entre os agrupamentos construídos. Como por exemplo, nota-se no Cluster 1 a maior predominância de agricultores cujas famílias moram na propriedade da Microbacia Mariana (91\%), já no Cluster 2 a maior predominância de agricultores em que as famílias moram na cidade de Alta Floresta (80\%) e não nas propriedades.

\subsection{MESMIS NA CONSTRUÇÃO DE INDICADORES DE SUSTENTABILIDADE}

Com o emprego da metodologia MESMIS - após estandardização, atribuição dos pesos e avaliação qualitativa dos indicadores - pôde-se montar o Gráfico Radar (Figura 5) com os índices ponderados dos indicadores envolvendo a visão dos agricultores (Clusters 1 e 2) e dos atores 


\section{CLUSTERIZAÇÃO DE SISTEMAS DE MANEJOS E A CONSTRUÇÃO DE INDICADORES DE SUSTENTABILIDADE UTILIZANDO A METODOLOGIA MESMIS NO TERRITÓRIO PORTAL DA AMAZÔNIA}

sociais urbanos. Verifica-se nesta figura que o único indicador que está enquadrado na condição de "sustentável ou ótimo" é o "interesse das famílias dos agricultores em revegetar as APPs": Cluster 1 (100\%) e Cluster 2 (89\%). Visão semelhante também dos atores urbanos (80\%).

Vê-se na Figura 5 que os agricultores dos dois agrupamentos identificados têm a mesma percepção sobre a maioria dos indicadores considerando-os como baixa ( $33 \%$ do valor ideal a ser alcançado) que acompanham também a interpretação do olhar dos atores sociais urbanos. Entretanto, diverge mais fortemente desses porque atribuíram uma avaliação de 53\% dos agroecossistemas relativo aos indicadores (1) $\mathrm{N}^{\circ}$ de pessoas que moram e exploram as UPs, (2) percepção quanto a capacidade suporte das pastagens e (3) Credibilidade), (4) $46 \%$ (disponibilidade de recursos próprios para recuperar as APP e percepção quanto ao assoreamento dos rios) e (5) $40 \%$ (acessibilidade ao crédito rural, serviços de ater, diversidade agrícola, rentabilidade, percepção quanto a fertilidade dos solos).

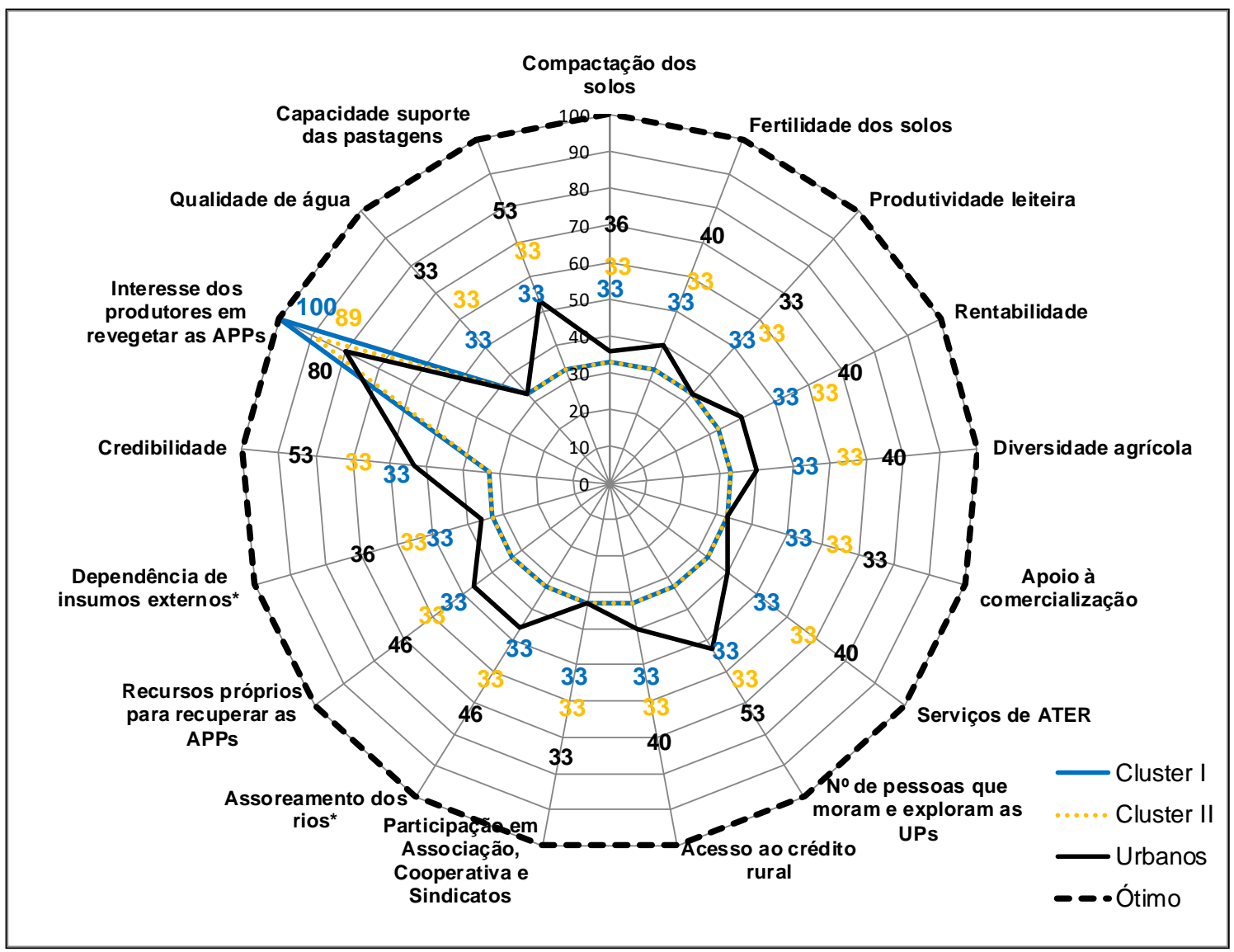

Figura 5 - Índice ponderado por indicador e por sistema de manejo atribuído pelos agricultores. Alta FlorestaMT. Fonte: Os autores (2014).

Os demais indicadores foram avaliados pelos dois agrupamentos como "não sustentável", com índices de sustentabilidade socioambiental que variaram entre $26 \%$ e $33 \%$.

Percebe-se, com esses índices, que o processo avaliativo dos atores urbanos diverge dos clusters, sobretudo quanto aos indicadores " $n$ o de pessoas que moram e exploram as UP, Capacidade suporte das pastagens e Credibilidade" possivelmente devido a falta de conhecimento da realidade local dos agentes externos. 


\section{CLUSTERIZAÇÃO DE SISTEMAS DE MANEJOS E A CONSTRUÇÃO DE INDICADORES DE SUSTENTABILIDADE UTILIZANDO A METODOLOGIA MESMIS NO TERRITÓRIO PORTAL DA AMAZÔNIA}

Estudo realizado por Neri-Noriega et al. (2008), no município de Tepeaca no Estado de Puebla, México fazendo comparação do estado de sustentabilidade nas áreas irrigadas de "El Chamizal" e "Lázaro Cárdenas" detectou que a primeira localidade estava com sua diversidade agrícola próximo do ótimo (90\%) porque os agricultores manejavam 18 cultivos, enquanto que a segunda área estava afastada do ideal como $45 \%$. Este resultado está mais próximo do encontrado na MBM, cujo indicador alcançou o índice de $28 \%$ (Cluster 1) e 31\% (Cluster 2).

No tocante ao indicador "dependência de insumos", Muner (2011), obteve resultados similares caracterizando zonas agricultores de café arábica no Estado do Espírito Santo, comparando a sustentabilidade socioeconômica e ambiental entre o cultivo do café arábica: convencional, orgânico e de boas práticas agrícolas. O autor encontrou comportamento semelhante deste indicador aos da MBM, obtendo índice ponderado de $38 \%$ no sistema "Boas Práticas Agrícolas" e 45\% no cultivo convencional. No estudo, destacou-se, de forma positiva, o sistema orgânico com índice ponderado de $69 \%$, enquadrando-se na condição "estável".

Estudos realizados por Abreu et al. (2011), quanto ao grau de deterioração social de 23 famílias na Microbacia Hidrográfica Riacho da Igreja, município de Cabaceiras/ PB, detectaram o índice de 47,7\%. Conduta semelhante à recomendada por Abreu e colaboradores, precisa ser adotada na MBM, onde os pesquisadores ressaltam “... para todas variáveis estudadas, haverá necessidade da intervenção do poder público e/ou da sociedade organizada para que de forma articulada possam implementar medidas direcionadas para solução dos problemas encontrados." (Abreu et al., 2011, p.27).

\section{CONCLUSÕES}

Com as ferramentas da análise multivariada identificaram-se dois agrupamentos que apresentaram características semelhantes com os seguintes comportamentos:

Cluster (1): Agrupamento formado por agricultores que utilizam melhor os recursos tecnológicos se comparado ao grupo 2, alto emprego da mão de obra e com razoáveis propriedades químicas de solo na área de entorno e de APP. Sendo este o perfil mais frequente dos agricultores analisados $(n=45$, cerca de $80 \%$ da amostra);

Cluster 2): Agrupamento formado por agricultores com baixa riqueza tecnológica que estão há mais tempo na propriedade e adquiriram lógica mais sustentável para a derrubada das matas ciliares. Tendo um elevado valor das propriedades químicas tanto na área de entorno quanto na área de APP. Sendo este o perfil menos frequente dos agricultores analisados ( $n=11$, cerca de $20 \%$ da amostra).

$\mathrm{Na}$ avaliação da sustentabilidade da MBM, conforme metodologia MESMIS, percebese que os agricultores de ambos os clusters têm a percepção de que a MBM encontra-se degradada social e ambientalmente, tendo em vista o índice ponderado de 35\% (Cluster 1) e 35,2\% (Cluster 2). Os atores sociais urbanos também têm a mesma visão, haja vista o índice ponderado de $38 \%$ por eles atribuído.

Obviamente que há plena consciência de que um índice não refletirá $100 \%$ a realidade do ambiente pesquisado, pois ele simplifica a análise em apenas um valor numérico. Todavia, seguramente, ele informa a "temperatura do corpo", ou seja, como se encontra o grau de degradação socioambiental, se está normal, febril ou muito febril. Deste modo, o ISS geral da MBM (média dos agricultores e atores sociais urbanos) aponta que o estado da MBM é febril (não sustentável), haja vista o índice ponderado médio de $36,8 \%$. Os dados encontrados corroboram a hipótese defendida de que as unidades produtivas da MBM encontram-se degradadas social e ambientalmente requerendo a implementação de políticas públicas dentro de um processo dialógico e co-evolucionista, na perspectiva de se alcançar o desenvolvimento de forma sustentável.

\section{AGRADECIMENTOS}

Os autores agradecem aos agricultores da Microbacia Hidrográfica Mariana que participaram da pesquisa, a Fundação de Amparo à Pesquisa do Estado de São Paulo (FAPESP) e Coordenação de Aperfeiçoamento de Pessoal de Nível Superior (Capes), respectivamente, pela 


\section{CLUSTERIZAÇÃO DE SISTEMAS DE MANEJOS E A CONSTRUÇÃO DE INDICADORES DE SUSTENTABILIDADE UTILIZANDO A METODOLOGIA MESMIS NO TERRITÓRIO PORTAL DA AMAZÔNIA}

bolsa Doutorado e a bolsa Doutorado Sanduiche concedida ao primeiro autor.

\section{REFERÊNCIAS}

ABREU, B.S.; FERNANDES NETO, S.; MELO, A.A.; MELO, G.K.R.M.M.; LIMA, P.C. S.; MORAIS, P.S.A.; OLIVEIRA, Z.M. Diagnóstico socioeconômico da Microbacia Hidrográfica Riacho da Igreja, Cabaceiras/PB. Revista Educação Agrícola Superior, Brasília, v.26, n.1, p.25-29, 2011.

ALVARES, C.A.; STAPE, J.L.; SENTELHAS, P.C.; GONCALVES, J.L. de M.; SPAROVEK, G. Köppen's climate classification map for Brazil. Meteorologische Zeitschrift, Johannesburg, v.22, n.6, p.711-728, 2014.

APHA (American Public Health Association). In: Clescere, L.S., Creenberg, A.E.,Eaton, A.D. (Eds.), Standard methods for the examination of water and wastewater. 20 ed. United Book Press, Inc. APHA, AWWA, WEF., Baltimore, Maryland. 1988.

ASTIER, M.; MASERA, O.R.; GALVÁN-MIYOSHI, Y. (Coord.). Evalución de sustentabilidad: un enfoque dinámico y multidimensional. Fundación Instituto de Agricultura Ecológica y sustenable. España, 2008.

BLEICH, M.E., SILVA, C.J. Caracterização dos fragmentos florestais amazônicos remanescentes na microbacia hidrográfica do rio Taxidermista I em Alta Floresta,MT. Biotemas, Florianópolis, v.24, p.41-51, 2013.

CAMARGO, M.F.; ROQUE, C.G.; UMETSU, R.K.; PIERANGELI, M.A.P.; SILVA, T.R.C.da. Fertilidade do solo da área ciliar da sub-bacia hidrográfica Mariana, para fins de conservação ambiental. Revista Ambiente \& Água, Taubaté, v.5, p.57-67, 2010.

CERÓN, W. L., TRUJILLO, A.R., ESCOBAR, Y.C. Aplicación del índice de sostenibilidad del recurso hídrico en la agricultura (ISRHA) para definir estrategias tecnológicas sostenibles en la microcuenca Centella. Ingeniería y Desarrollo, Colombia, v.30, n.2, p.160-181, 2012.

DORAN, J.W., PARKIN, T.B. Defining and assessing soil quality. In: DORAN, J.W.; COLEMAN, D.C.; BEZDICEK, D.F.; STEWART, B.A. (Ed.). Defining soil quality for a sustainable environment, n.35, p.322, 1994.
EMBRAPA. Manual de métodos de análise de solo. Rio de Janeiro: EMBRAPA Solos, 1997.

ESQUIVEL, C.E.G., GRANADOS, H.R. ¿Es posible evaluar la dimensión social de la sustentabilidad? aplicación de una metodología en dos comunidades campesinas del Valle de Toluca, México. Convergencia. Revista de Ciencias Sociales, Maracaibo, Venezuela, v.13, n.40, p.107-139, 2006.

FASIABEN, M.do C.R.; MAIA, A.G.; ROMEIRO, A.R.; MORAES, J.F.L.; TAMBOSI, L.R. Remanescentes de vegetação natural em diferentes tipos de unidades de produção agropecuária na microbacia do rio Oriçanga, Estado de São Paulo. Rev. de Economia Agrícola, São Paulo, v.57, n.2, p.63-80, 2010.

FERRARI, P.A., MANZI, G. Nonlinear principal component analysis as a tool for the evaluation of customer satisfaction. Quality technology \& quantitative management, v.7, n.2, p.117-132, 2010.

FERREIRA, G.B.; COSTA, M.B.B.; SILVA, M.S.L.; MOREIRA, M.M.; GAVA, C.A.T.; CHAVES, V.C.; MENDONÇA, C.E.S. Sustentabilidade de agroecossistemas com barragens subterrâneas no semiárido brasileiro: a percepção dos agricultores na Paraíba. Rev. Bras. de Agroecologia, Pelotas, v.6, n.1, p.19-36, 2011.

GALVÁN-MIYOSHI, Y. Integración de indicadores en la evaluación de sustentabilidad: de los índices agregados a la representación multicriterio. In: ASTIER, M., MASERA, O.R., GALVÁN-MIYOSHI, Y. (Coord.). Evalución de sustentabilidad: un enfoque dinámico y multidimensional. Fundación Instituto de Agricultura Ecológica y sustenable. Valência: Mundiprensa, 2008. cap. 6, p.95-115.

GASTAL, M.I.; XAVIER, J.H;V.; ROCHA, F.E.C.; MOLINA, M;C.; ZOBY, J.L.F. Método participativo de apoio ao desenvolvimento sustentável de assentamentos de reforma agrária. Planaltina: Embrapa Cerrados, 2002.

GUIMARÃES NETO, R.B. A lenda do ouro verde: política de colonização no Brasil contemporâneo. UNICEM, Cuiabá, 2002.

GUIMARÃES, R.P.; FEICHAS, S.A.Q. Desafios na construção de indicadores de sustentabilidade. Ambiente \& Sociedade, Campinas, v.12, n.2, p.405-414, 2009. 


\section{CLUSTERIZAÇÃO DE SISTEMAS DE MANEJOS E A CONSTRUÇÃO DE INDICADORES DE SUSTENTABILIDADE UTILIZANDO A METODOLOGIA MESMIS NO TERRITÓRIO PORTAL DA AMAZÔNIA}

HAIR, J.F., ANDERSON, R.E., TATHAM, R.L. Análise multivariada de dados. Porto Alegre: Bookman, 2005.

HUMBERTO, T.; RODRIGO, G.F.; JORGE, M.; RAMÓN, G. Indicadores de sustentabilidad para la producción lechera familiar en Uruguay: análisis de tres casos. Agrociencia, Montevideo, v.16, n.1, p.166-176, 2012.

IBGE (Instituto Brasileiro de Geografia e Estatística). População 2010: informações completas. Disponível em: <http://www.ibge.gov.br/cidadesat/xtras/perfil.p hp?codmun $=510025 \&$ search $=$ mato-grosso $\mid$ altafloresta>. Acesso em: 02 de Jul. de 2016.

IBGE. Manual técnico da vegetação brasileira. Rio de Janeiro: IBGE, 2012.

IORI, P.; DIAS JÚNIOR, M.de S.; SILVA, R.B. da. Resistência do solo à penetração e ao cisalhamento em diversos usos do solo em áreas de preservação permanente. Biosci. J., Uberlândia, v.28, p.185-195, 2012.

KARLEN, D.L.; STOTT, D.E. A framework for evaluating physics and chemical indicators of soil quality. In: DORAN, J.W.; COLEMAN, D.C.; BEZDICEK, D.F.; STEWART, B.A. (Ed.). Defining soil quality for a sustainable environment. Soil Science Society of American, Madison, p.53-71, 1994.

LÓPEZ-RIDAURA, S., MASERA, O., ASTIER, M. Evaluating the sustainability of complex socioenvironmental systems. the MESMIS framework. Ecological Indicators, v.2, p.135-148, 2002.

MINGOTI, S.A. Análise de dados através de métodos de estatística multivariada: uma abordagem aplicada. Belo Horizonte: UFMG, 2005.

MUNER, L.H. Sostenibilidad de la caficultura arábica en el ámbito de la agricultura familiar en el Estado de Espírito Santo - Brasil. 2011. Tese (Doctorado en Recursos Naturales y Desarrollo Sustentable) - Instituto de sociología y estudios campesinos, Universidad de Córdoba.

NERI-NORIEGA, R.; OCAMPO-FLETES, I.; ESCOBEDO-CASTILLO, J.F.; PÉREZ-MAGAÑA, A..; RAPPO-MIGUEZ, S.E.. La sustentabilidad de los sistemas agrícolas con pequeña irrigación: el caso de San Pablo Actipan. Ra Ximhai, México, v.4, n.2, p.139-163, 2008.
NUSH, E.A. Comparison of different methods for chlorophyll and phaeopig-ment determination. Arch. Hydrobiol, v.14, p.14-36, 1980.

OLIVEIRA, J.T.A. de. Lógicas produtivas e impactos ambientais: estudo comparativo de sistemas de produção. 2000. Tese (Doutorado em Engenharia Agrícola) - Faculdade de Engenharia Agrícola, Universidade Estadual de Campinas, Campinas.

$R$ CORE TEAM. R: A language and environment for statistical computing. $R$ Foundation for Statistical Computing, Vienna, Austria. Disponível em: <http://www.R-project.org/>. Acesso em: 20 jul. 2015.

RAMOS, F.T.; MONARI, Y.C.; NUNES, M.C.M.; CAMPOS, D.T. da S.; RAMOS, D.T. Indicadores de qualidade em um Latossolo Vermelho-amarelo sob pastagem extensiva no pantanal matogrossense. Revista Caatinga, Mossoró, v.23, n.1, p.112-120, 2010.

RAMOS, G.L.; SILVA, A.P.G.; BARROS, A.A.F. Manual de metodologia de extensão rural. Recife: Instituto Agronômico de Pernambuco, 2013.

RICHARDSON, R.J.; PERES, J.A. de S.; WANDERLEY, J.C.V.; CORREIA, L.M.; PERES, M.H.de M. Pesquisa Social: métodos e técnicas. São Paulo: Atlas, 2012.

ROBOREDO, D., BERGAMASCO, S.M.P.P., BLEICH, M.E. Aggregate index of social-environmental sustainability to evaluate the socialenvironmental quality in a watershed in the Southern Amazon. Ecological Indicators, v.63, p.337-345, 2016.

RONQUIM, C.C. Conceitos de fertilidade do solo e manejo adequado para as regiões tropicais. Campinas: Embrapa Monitoramento por Satélite, 2010.

ROSA, I; M.D.; PURVES, D.; SOUZA JUNIOR, C.; EWERS, R.M. Predictive modelling of con-tagious deforestation in the Brazilian Amazon. Plos One, San Francisco, v.8, p.1-14, 2013.

SARANDÓN, S.J. El desarrollo y uso de indicadores para evaluar la sustentabilidad de los agroecosistemas. In: SARANDÓN, S.J. (Ed). Agroecología: el camino hacia una agricultura sustentable. La Plata, Argentina: Ediciones Científicas Americanas, 2002. cap. 20, p.394-414. 


\section{CLUSTERIZAÇÃO DE SISTEMAS DE MANEJOS E A CONSTRUÇÃO DE INDICADORES DE SUSTENTABILIDADE UTILIZANDO A METODOLOGIA MESMIS NO TERRITÓRIO PORTAL DA AMAZÔNIA}

SARANDÓN, S.J.; ZULUAGA, M.S.; CIEZA, R.; GÓMEZ, C.; JANJETIC, L.; NEGRETE, E.. Evaluación de la sustentabilidad de sistemas agrícolas de fincas en misiones, Argentina, mediante el uso de indicadores. Agroecología, Múrcia, v.1, p.19-28, 2006.

SEPÚLVEDA, S. Biograma: metodología para estimar el nivel de desarrollo sostenible de territórios. San José: IICA, 2008.

SIEGEL, S., CASTELLAN, N.J. Nonparametric statistics for the behavioral sciences. New York, 1988.

SPEELMAN, E.N.; LÓPEZ-RIDAURA, S.; COLOMER, N.A.; ASTIER, M.; MASERA, O.R. Ten years of sustainability evaluation using the MESMIS framework: lessons learned from its application in 28 Latin American case studies. International Journal of Sustainable Development \& World Ecology, v.14, p.345-361, 2007.

STOLF, R. Teoria e teste experimental de formulas de transformação dos dados de penetrômetro de impacto em resistência do solo. Revista Brasileira de Ciência do Solo, Viçosa, v.15, p.229-235, 1991.

TOMPKIN, J.R. Estatística e métodos de pesquisa em ciências sociais rurais. Piracicaba: Escola Superior de Agricultura Luiz de Queiroz, 1967. [Mimeo]

VERONA, L.A.F. A real sustentabilidade dos modelos de produção da agricultura indicadores de sustentabilidade na agricultura. Hortic. bras., Vitória da Conquista, v.28, n.2, 2010.

YAO, R.J.; YANG, J.S.; ZHANG, T.J.; GAO, P.; YU, S.P.; WANG, X. Short-term effect of cultivation and crop rotation systems on soil quality indicators in a coastal newly reclaimed farming area. Journal of Soils and Sediments, v.13, n.8, p.1335-1350, 2013.

ZOBY J.L.G., OLIVEIRA, F.R. Panorama da qualidade das águas subterrâneas no Brasil. Brasilia: ANA, 2005. 